
\title{
$\triangle \begin{aligned} & \text { Western Undergraduate } \\ & \text { Research Journal }\end{aligned}$
}

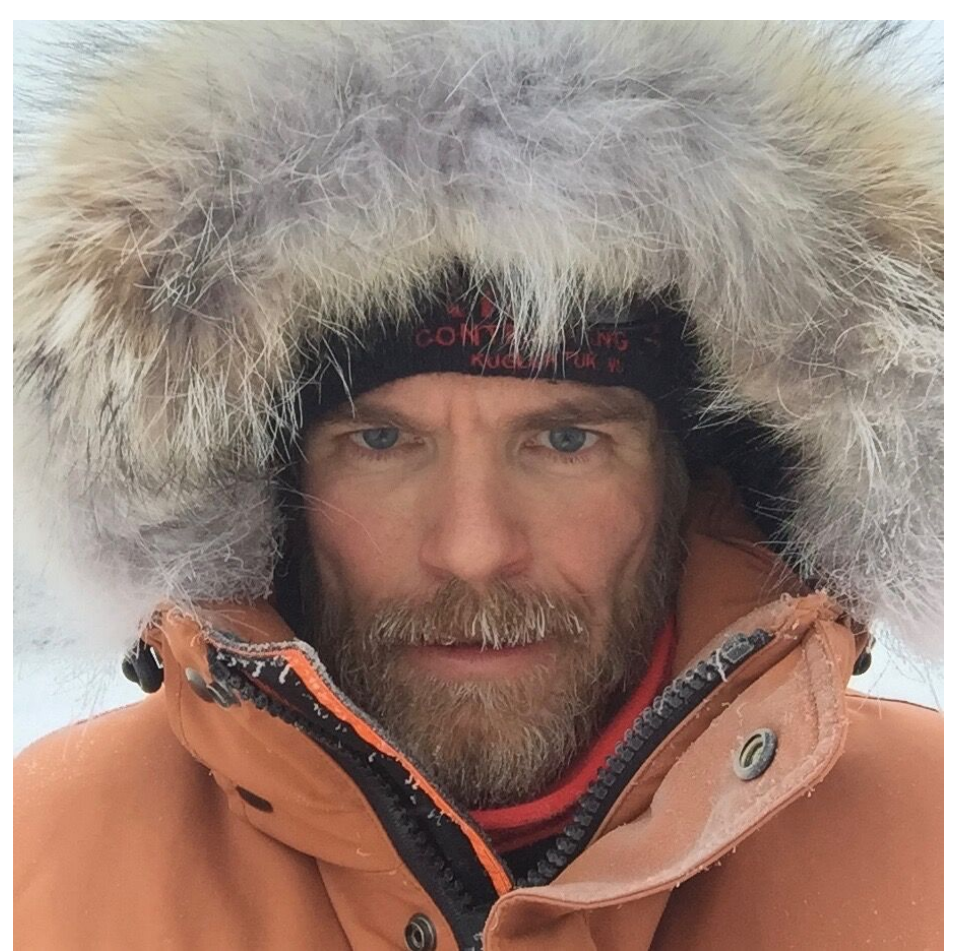

"The environment is moving into a different regime, and so we can no longer rely on the past to predict what's going to happen in the future. That means we have to understand things even more fundamentally than we ever have. Only when we understand the environment and the way the world works physically and biologically, can we then make predictions about what's going to happen when we change it."

\section{Background}

Dr. Branfireun finished his undergraduate degree in Physical Geography at Western in 1992, and had the opportunity to do fieldwork in the Canadian Rocky Mountains with Dr. Chris Smart during his second year. This solidified his interest in hydrology and water quality in watersheds. He received his Master's degree from York University, had the opportunity to do research in the Experimental Lakes Area, and began collaborating with other students who worked on metal contaminants. "I became interested in it, and we made some important discoveries in methyl mercury. That drew me in, and I became very motivated in studying mercury in the environment."

\section{Western Faculty Profile: Dr. Brian Branfireun}

\author{
Wilson $\mathrm{Ho}^{1}$ \\ ${ }^{1}$ Faculty of Science, Western University \\ No conflicts of interest declared.
}

Dr. Branfireun was a professor at the University of Toronto for 10 years, and came to Western University in 2010 after accepting the position as Canada Research Chair in Environment and Sustainability. "There's a greater emphasis on research, and I was at a stage in my career where I would enjoy more time to focus on that." He also directs a modern laboratory at the Biotron for the study of metals in the environment, such as mercury, arsenic, and chromium. "The Biotron provides some amazing opportunities and experimental spaces to simulate future climate, and I'm very interested in seeing how the environment would respond to these scenarios. We can treat soils and plants to warmer temperatures and higher carbon dioxide concentrations, and see how they respond. I was also able to setup a very sophisticated lab where we do all of our analyses for trace metals."

\section{What is your main research focus?}

"I am broadly an environmental scientist, but my primary interest is in mercury in the environment. I study the effects of land use change and water movement that affects the availability of contaminants, with a particular focus on metals. The work that I do focuses on understanding the transport of metals like mercury, arsenic, and chromium, how they make their way through the environment and ultimately into fish, and how they present a risk to consumers." 
There is a lot of complexity in the cycling of contaminants, and Dr. Branfireun focuses on learning how mercury transforms in the environment. "We've made lots of progress in understanding where and how inorganic mercury is converted into methyl mercury. Methyl mercury is the toxic form that bioaccumulates and biomagnifies in food chains.”

How did you get into Environmental Science, and researching mercury?

Studying mercury and metal contamination in water was not Dr. Branfireun's initial goal. "I didn't train to do that. That's not what my undergraduate education was, and that's not even what my research goals were as a graduate student. I thought that I was going to be a teacher in physical geography or environmental science. But then I had an opportunity to do fieldwork at Western during my second year, and I had so much fun doing that. I realized that this is what university professors get to do; they get to do research and they get to teach. It brought together something that I thought I was going to do, with something that I knew I wanted to continue doing."

Dr. Branfireun's work focuses strongly on mercury, and aims to form connections with people in different departments. "One of my goals is to more closely affiliate my work on mercury in the environment from a chemical perspective to ... people that do work on the biological side of the mercury problem. I wanted to understand how contaminants move through lower trophic levels to work their way up into fish, and I was very interested in being able to tell the complete story."

Although we have deep knowledge about the biochemical processes involved in metal cycles, the physical environment still holds many secrets. "You can have two lakes right beside each other; one of them has mercury in fish that are above levels fit for human consumption and the other lake can be below that limit. The differences can't be just because of different amounts coming from the atmosphere since they're right beside each other. Something different about the biology of the lake, like the number of bio-accumulating steps in the food chain, can make a huge difference in how much mercury gets to the top fish. I don't have all of this expertise, and that means that I can't tell the whole story. My collaborators and I work together to try to understand the whole picture."

What is the most rewarding part of being an Environmental Scientist?

Dr. Branfireun is currently making progress at understanding why mercury in fish is different among lakes in different parts of Canada, and this allows him to make predictions about the future. "A lot of the work that I am now doing is with First Nations communities. A lack of scientific information on which fish are safe to eat is very unsettling for people, and it is a very frustrating and concerning situation if you don't have information on the safety and quality of the food that you rely on. It's emotionally hard sometimes to work with people who truly fear for the future of their communities and the land where they live. I think that's a reality check, especially for those of us who have the comforts of our lives here in the south. We can be concerned about things, but I think that it's very difficult for any of us to truly empathize and understand situations like this. Those of us who are privileged and have an opportunity to try and improve those situations have an ethical obligation to try and do so."

In addition to working with the community itself, Dr. Branfireun is also working with the government as an expert on environmental issues like mercury and climate change. "It's very satisfying to have your research be used in a meaningful way, and help government agencies make better decisions about what to do with mercury in the environment. Research allows me to become an expert, and as an expert I can then make some contribution to the way that decisions are made." 
What is the most difficult part of being an Environmental Scientist?

"It can be very hard to have things that we know as scientific fact be ignored in policy and regulatory action. It's frustrating to do your best to inform people about the science that's involved, and have it treated not as important as we think it should be treated. Science is embedded in society, which is also influenced by other social and economic trends and priorities. I can only hope that the work that I, and thousands of other people do, continue to move forward and keep the world as habitable as it can be. We're facing many challenges with respect to climate change, and we have to stay positive and optimistic to continue making contributions that can be useful."

Dr. Branfireun recounts a recent trip that he took to the Northwest Territories, where he did flyin work on lakes. "Although field work can be very hard, I find it to be the most satisfying thing that I do because you only focus on things that need to be done at that point in time. The things that need to be done are collect your samples, take good notes in your field book, feed yourself, be sheltered, and chop wood. You're disconnected from the rest of the world, which is physically challenging but at the same time very rewarding."

\section{What advice do you have for undergraduates?}

For anyone who wants to become more knowledgeable in anything, Dr. Branfireun recommends finding an expert, and speaking with them. "You shouldn't hesitate to approach your professors or your TAs. There are always opportunities for students to become involved in things, and I think you have to become physically involved in it. I couldn't have known in my second year that I loved going into the Canadian Rockies for 6 weeks as much as I did. It was intimidating and scary to think about, but it was an opportunity that I didn't want to miss. I also know many students who have taken opportunities like that, and realized it wasn't what they want to do. You have to take the opportunity to get the real experience in things you think you might be interested in. Create the opportunities to do it, and do it.”

"The idea that you stay on the same course over your life and your career is not true. You take the knowledge that you have, and you go in the directions that you want. If you don't have the expertise or knowledge, then you acquire it somehow. There aren't rules about this, but you have to work hard and you have to love what you do. The only way to determine what it is that you truly love is to get experience in doing lots of different things."

To read more on Dr. Branfireun and his research, please visit his website at:

https://www.uwo.ca/biology/directory/faculty/branfireun.html 